\title{
CHILDREN MAKE VIDEO ABOUT SILVER DIAMINE FLUORIDE
}

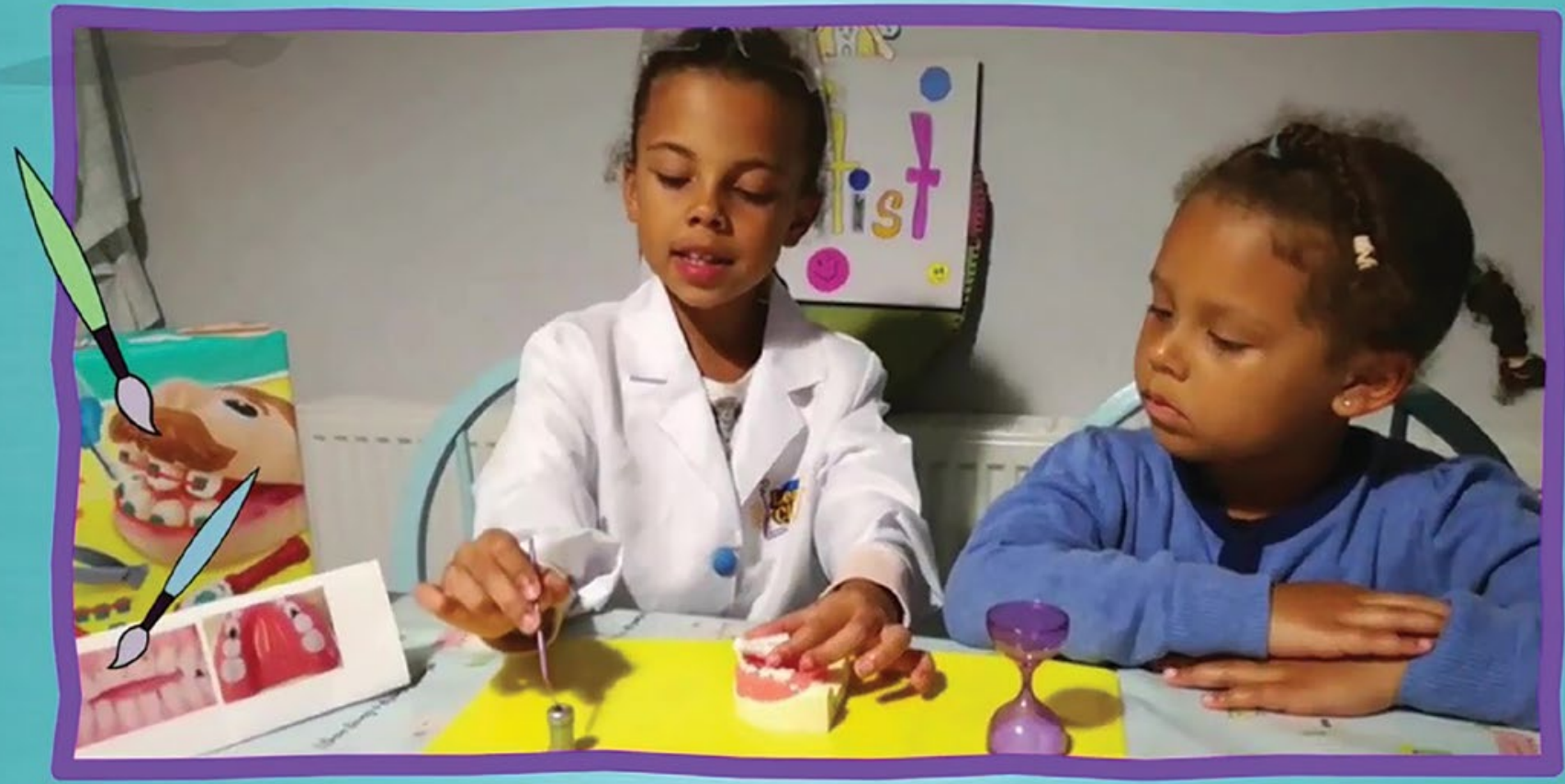

$$
\text { we're going to be pelisiting ithe tooth with the holes. }
$$

A video has been made by staff at the School of Clinical Dentistry at the University of Sheffield to explain treatments for dental decay in children, co-produced with a team of children aged between three and 11.

The staff and children worked with a professional film editor to produce a sixminute video focusing on silver diamine fluoride (SDF) as a technique for arresting dental caries.

Two adults feature in the film. One is Professor Paul Hatton, a materials scientist, who filmed himself in his lab at the University of Sheffield. The other is paediatric dentist Laura Timms, the academic clinical fellow who was instrumental in making the video, having been awarded a grant of $£ 5,460$ jointly by the Faculty of Dental Surgery (FDS) of the Royal College of England RCS (Eng) and the British Society of Paediatric Dentistry (BSPD) for her proposal.

In 2019, Laura decided to research SDF and, with colleagues in Sheffield and
Newcastle, wrote a paper ${ }^{1}$ examining why SDF is not being used more widely in the UK. Working with the trainee group that she belongs to, CONNECT TRAINEES, she led a research project exploring paediatric dentists' attitudes to SDF and in May 2020 she delivered a webinar on the topic to the group.

Explaining how the video was made, Laura said: 'We sent the children and their parents a child-friendly instruction pack with visual and written information about tooth decay and treatment options, along with modelling clay, a toy dental surgery and other dental props to use as they liked. We asked them to explain dental decay and how it's treated and to describe SDF. Within that brief, they were given a completely free rein.'

Initially, she said, they had four hours of filmed activity which was gradually edited down to six minutes, with the children directing what they liked and didn't like. As an example of the children's input, a seven-year-old created her own pie chart to illustrate the extent of dental decay in children. Also, to illustrate dental decay, they were given a colour photo showing a palatal view of a child's teeth. However, unlike dentists, the children were not familiar with this view and requested one that showed a child's smile from the front. The children's creativity and expertise was really impressive and covered everything from their outfits, to the music and the graphics.

The Sheffield team hope that the video will provide accessible information about SDF for children and their families so they can make informed choices about treatment for decayed primary teeth.

The video can be viewed at https://www. bspd.co.uk/News-Media/Videos.

\section{Reference}

1. Timms L, Sumner O, Deery C, Rogers $\mathrm{H} \mathrm{J}$. Everyone else is using it, so why isn't the UK? Silver diamine fluoride for children and young people. Community Dent Health 2020; 37: 143-149. 